\title{
Building bridges between experts and the public: a comparison of two-way communication formats for flooding and air pollution risk
}

\author{
Maria Loroño-Leturiondo ${ }^{1}$, Paul O'Hare ${ }^{1}$, Simon J. Cook ${ }^{2}$, Stephen R. Hoon ${ }^{1}$, and Sam Illingworth ${ }^{1}$ \\ ${ }^{1}$ School of Science and the Environment, Manchester Metropolitan University, Manchester, M1 5GD, UK \\ ${ }^{2}$ Geography, School of Social Sciences, University of Dundee, Dundee, DD1 4HN, UK
}

Correspondence: Maria Loroño-Leturiondo (m.lorono.leturiondo@mmu.ac.uk)

Received: 19 April 2018 - Discussion started: 18 May 2018

Accepted: 14 January 2019 - Published: 24 January 2019

Abstract. Urban centres worldwide are adversely affected by flooding and air pollution. Better-prepared citizens are crucial to limiting the impacts of these hazards, and both lay knowledge and personal experiences are important in complementing and challenging expert opinion. For the first time, this study offers a critical comparison of how different twoway communication formats have been used worldwide between experts and the public in relation to flooding and air pollution risk. Through a systematic review, we analyse social media, educational programmes, serious games, citizen science, and forums in terms of their effectiveness in respect of dealing with incidents, raising awareness, and promoting knowledge exchange in the context of flooding and air pollution risk. We find that there is neither a one-size-fits-all nor superior format of communication. No single format is effective in fulfilling all three communication purposes. All five formats analysed appear to be successful under different circumstances and are never suitable for all segments of the population. Communication between experts and the public is difficult and full of tensions; information alone is not enough. Our study shows different ways of incorporating strategies to build trust between experts and the public and make communication more fun and accessible, breaking down hierarchies and creating safe spaces for co-creation where everyone feels empowered to participate and everyone benefits.

\section{Introduction}

Flooding and air pollution represent serious concerns for many urban populations worldwide and are aggravated, for example, by climate change, growing populations, and increasing urbanisation (Committee on Climate Change, 2016; World Economic Forum, 2016). The localisation of flooding and air pollution impacts imparts responsibility jointly upon local governments, citizens, and other relevant stakeholders (Butler and Pidgeon, 2011; Johnson and Priest, 2008). Citizens should be instrumental in driving local solutions and in tackling these two environmental challenges. Not only do citizens possess highly pertinent local and personal on-theground experience and knowledge, but also when they are aware and prepared they become key to limiting the damage that a specific hazard brings to people, the economy, and the environment (Bickerstaff, 2004; Burningham et al., 2008; Environment Agency, 2001; O'Hare et al., 2016).

Through a systematic review, we have selected and analysed 50 articles on two-way communication between experts and the public in the context of flooding and air pollution. For the first time, we offer a comparison of how five different communication formats can be used for dealing with incidents, raising awareness, and promoting knowledge exchange; we also explore differences in communication possibilities between these two different hazards.

The awareness and preparedness campaigns for flooding and air pollution have followed the premise that if citizens have information, they will be aware, prepared, and ready to take action (Bickerstaff, 2004; Burningham et al., 2008). This aligns with a "deficit model" in which citizens are pas- 
sive receivers of information and experts fill the knowledge gap through a one-way form of communication to the public (Miller, 2001). However, citizens are not passive receivers of information; they are active, critical, have values and beliefs, and possess lay knowledge as well as relevant previous experiences (Longnecker, 2016), in this case, of floods and the effects of air pollution. One-way provision of information does not, therefore, realise the full potential of knowledge transfer. The discrepancies in information on people's personal experiences of flooding or air pollution, together with an excessive use of technical language and the challenge of presenting ambiguity and uncertainty in complex topics, are some of the factors that can debilitate the communication process (Bickerstaff, 2004; Bickerstaff and Walker, 1999; Burningham et al., 2008). The existing climate of mistrust between the public and (some) experts is another factor that can limit the effectiveness of communication (Bickerstaff, 2004; Goodwin and Dahlstrom, 2014; Slovic, 1999; Weingart and Guenther, 2016). The government and the media, for instance, are not seen as being very trustworthy, mostly due to a suspicion about their respective political agendas, which may be at odds with doing their best for the public good (e.g. Bickerstaff, 2004; Bickerstaff and Walker, 1999).

Promoting local perspectives and on-the-ground experiences and facilitating knowledge exchange between experts ${ }^{1}$ and non-experts is key in reducing risks associated with flooding and air pollution, but a challenge nonetheless. Public engagement for knowledge exchange purposes has proven to be governed by an incapacity to create a non-hierarchical and safe space for co-creation in which the public feels empowered to contribute knowledge and the experts are dissociated from the authoritarian figure (Whatmore and Landström, 2011). Genuine knowledge exchange requires a "substantial" approach to public engagement, in order to "improve the quality of decision-making, to create more socially robust scientific and technological solutions" (Wilsdon and Willis, 2004, p. 39). In this approach, active citizens are subjects rather than objects in the governance of science and technology. Specifically, substantial public engagement would require (1) a public that is encouraged to deliberate jointly with the experts in contrast to only being allowed to voice an opinion; (2) agreement that the goal is to reach consensus between the two (or more) parties involved, and not just exploring different views; (3) breaking knowledge hierarchies and actively promoting the experiences, opinions, and agendas of experts and non-experts equally; and (4) inclusion of under-represented groups or groups who usually hold more critical, strong, and dissimilar views (Wilsdon and Willis, 2004, p. 39). In other words, if participation is not to be an empty and vacuous process it must come hand-inhand with a redistribution of power. Levels of participation have been represented by the metaphor of a ladder. On the

\footnotetext{
${ }^{1}$ By experts we include anybody who investigates, works with, or manages flooding and air pollution.
}

first rungs, there are efforts to educate people. These are followed by citizen consultation initiatives, where citizens have a say, but where it is uncertain how, or whether, those views are incorporated. The highest rung represents citizen control, beyond an equal partnership with traditional power holders (Arnstein, 1969). This highest form of participation may be expressed in terms of partnership between citizens and traditional power holders, when the process becomes a negotiation.

Central to this line of work is the need to move away from one-way provision of information and explore how two-way communication can be established. There is a need to examine which two-way communication formats are available, and to ascertain which of these are more suitable for raising awareness and which would allow substantial engagement and expert-public knowledge partnerships. It is also important to identify and investigate the actors of two-way communication processes, and those who initiate or control these communication processes. Whilst several recent studies have focused on one communication format in particular (e.g. Bosschaart et al., 2016; Breuer et al., 2017; Leon et al., 2015; Lo et al., 2013; Sîrbu et al., 2015) and on either flooding or air pollution individually - with some exceptions combining multiple hazards (Rodriguez Bermúdez et al., 2015) - our systematic review offers an overview of possibilities. This study offers a comparison across five different formats embracing two very different hazards: flooding and air pollution. Flooding is discrete in time, visual, and tangible as it has direct consequences on people and infrastructure, whereas air pollution is more difficult to grasp as it is a continuous threat, generally invisible in many urban centres, and has non-immediate health impacts. Different studies show how sensory cues (visual or olfactory) are necessary for people to relate to the otherwise intangible air pollution (e.g. Bickerstaff and Walker, 2001). Studies also explain how participants who link flooding to climate change are more likely to relate to this issue, due to the invisibility of climate change and the visibility of flooding (e.g. Whitmarsh, 2008).

\section{Two-way communication in flooding and air pollution: a systematic review}

\subsection{Search strategy}

Systematic reviews have become an increasingly popular research method in relation to climate change. In such a review a study pool is created based on a well-defined search protocol and a set of inclusion and exclusion criteria (Boland et al., 2013; Ford et al., 2011; Groulx et al., 2017; Lumbroso et al., 2017; Petticrew and Roberts, 2005). The metadata searches for this systematic review were conducted in two large and multidisciplinary academic databases: Scopus and Web of Science. This review emulates the technique used by Groulx et al. (2017), as their analysis of the different learning outcomes of citizen science projects is similar in approach to 


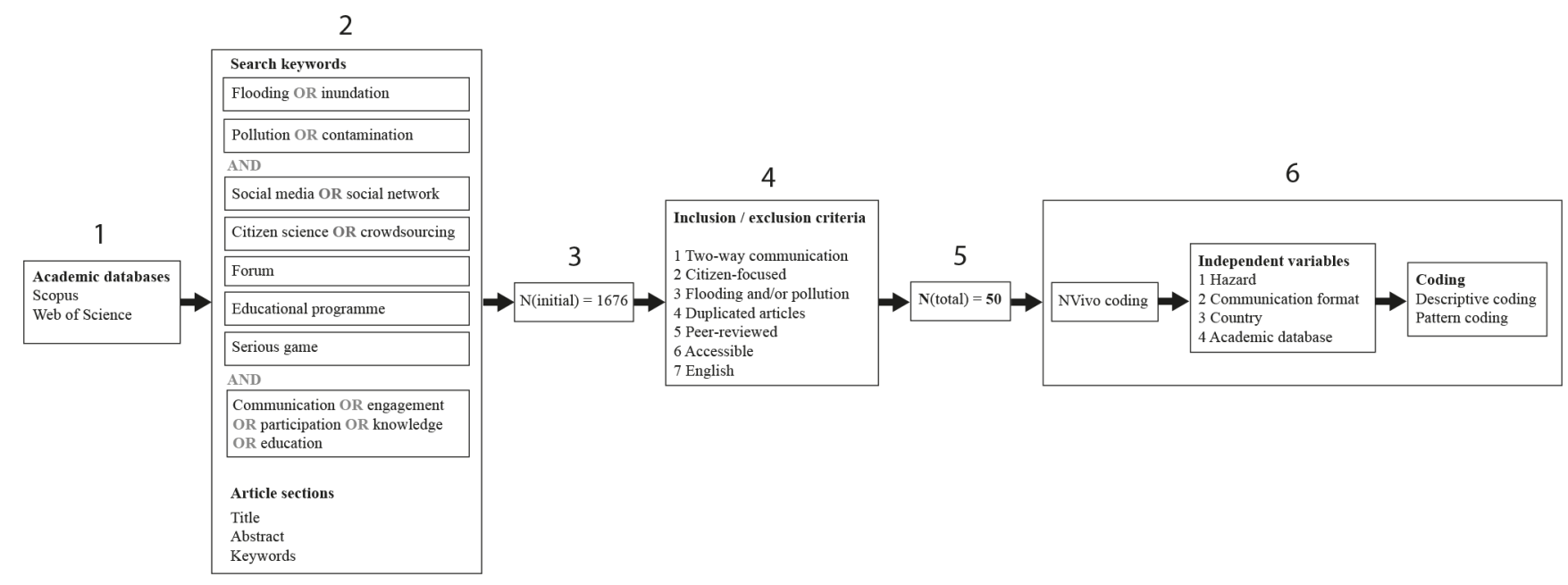

Figure 1. Overview of the systematic review methodology, stating (1) in which academic databases the search was conducted, (2) the different selected search keywords and in what parts of the articles the search keywords were looked for, (3) the initial number of retrieved articles, (4) the applied inclusion and exclusion criteria, (5) the final number of articles to be analysed, and (6) the coding exercise.

our aim of investigating communication outcomes of different two-way communication formats. The process followed in the systematic review is outlined in Fig. 1.

Our systematic review was limited to formats that allow two-way communication, where there are two "communicators" who issue and receive information (Bowater and Yeoman, 2012). Two-way communication can take many forms, but for the purpose of this review we accepted anything from face-to-face dialogues, to communication composed through posts and comments in social media. These formats include social media, educational programmes, discussion forums (collaborative encounters where experts work closely with affected communities; Whatmore and Landström, 2011), serious games (those which exceed mere entertainment purposes and also intend to educate; Abt, 2002), and citizen science projects, which can be described as "collaborative research that involves members of the general public (or citizens), and which actively involves them collecting, generating, and analysing data" (Illingworth and Allen, 2016, pp. 512). This list of formats was informed by an initial literature review of the field (Amri et al., 2017; Aubert et al., 2015; Fohringer et al., 2015; Gravina et al., 2017; Mani et al., 2016; McCormick, 2012; Pennington et al., 2015; Salvati et al., 2016; Whatmore and Landström, 2011), and in discussion with stakeholders in urban risk management, namely the Association of Greater Manchester Authorities (AGMA). The initial literature review also revealed that the search strategy had to account for terminological synonyms and alternative denominations. For example, "flood" is often used interchangeably with "inundation". Finally, the literature review elucidated that other terms had to be considered together with "communication", such as engagement, participation, knowledge, and education. Search keywords were linked using the Boolean operators AND/OR, and search was programmed to retrieve articles containing these search terms in the title, abstract, and keyword sections.

\subsection{Article inclusion criteria}

Not all the articles retrieved in these searches were relevant and thus a set of seven inclusion criteria was designed (Fig. 1, box 4):

- Criterion 1 (two-way communication) was designed to include only articles addressing two-way communication. For example, articles dealing with flyers and leaflets in mailboxes as educational propaganda were retrieved under the term "educational programmes", but these formats do not permit interaction between experts and non-experts.

- Criterion 2 (citizen-focused) ensured that articles were only included where they explained how the communication process impacted the citizen. For example, explaining how participants became more aware of a risk or how their input was incorporated into policy. Articles dealing with data mining, in which users do not realise that their data were being taking into consideration, were discarded.

- Criterion 3 (flooding and/or pollution) was included so that only articles dealing with flooding and air pollution were selected. Sometimes, other types of pollution, such as water pollution, came up. Additionally, HIV prevention campaigns were retrieved under the category "contamination" (terminological synonym of pollution) although they were not relevant for our study.

- Criterion 4 (duplicated articles) removed duplicate articles. Some of the articles came up under two different 
communication formats when these were used simultaneously, and had to be removed from the secondary category.

- Criterion 5 (peer-reviewed) assessed whether the article was published in academic and peer-reviewed literature.

- Criterion 6 (accessible) was related to accessibility, and how the articles had to be either open-access, available through the Manchester Metropolitan University library, or fully and freely accessible through ResearchGate via author elective uploads.

- Criterion 7 (English) ensured that only articles written in English were considered.

\subsection{Coding the articles}

The articles were coded for qualitative data analysis using the NVivo software. All the articles were assigned four independent variables: country, hazard (flooding or air pollution), format of communication (social media, serious games, educational programmes, citizen science, or forums), and academic database (Scopus or Web of Science). The coding exercise was developed in two cycles. Firstly, the data were analysed through a method called "descriptive coding", which allows the attribution of a label that describes the basic theme of a paragraph. Secondly, the data were later re-coded using a method called "pattern coding" (Saldana, 2009), finding relationships between codes and grouping data into more meaningful units. The coding exercise took place first with the articles retrieved from Scopus, and the articles in Web of Science were used to prove data saturation (Bryman, 2012).

All the articles analysed in the systematic review can be found in Table 1.

\section{Results of the systematic review}

\subsection{Social media: incident-related knowledge exchange, response coordination, and raising awareness}

Social media can be used for short-term communication in the case of an imminent or ongoing incident, such as flooding (e.g. Bunce et al., 2012) or air pollution crisis (e.g. Zhang et al., 2014). Most examples which involve emergency communication come from flooding and only relatively few from air pollution. Most often, air pollution is an ongoing problem and thus social media is used with a long-term focus (e.g. Fedorenko and Sun, 2016).

The articles show that when social media is used for shortterm communication, it can be done so with three different aims. (1) It can be used to share warnings and information in relation to an incident. For example, during the 2011 Queensland (Australia) floods, the Queensland Police Service used their Facebook page as the main channel for emergency communication, allowing citizens to "access, post and share information about road closures, flood peaks", etc. (Bunce et al., 2012, p. 37). Similarly, during the flooding in Thailand in 2011, social media was used for sharing information and advice on how to behave and what actions to take either from other more experienced citizens or from official sources: "victims shared the photos of their homes and the flood, and the knowledgeable ones uploaded their advice and analysis about the situation" (Leong et al., 2015). (2) Social media can also be employed by experts (e.g. government officials or response teams) to communicate with affected citizens and neighbours and collect on-the-ground information regarding the situation during and after a flooding incident, which can help provide a more accurate response to the situation (Rizza and Pereira, 2014; Yadav and Rahman, 2016). Social media is also used by affected populations to share emotions, and consequently by government officials to observe citizens' physical and psychological well-being during a crisis. During the 2013 Southeast Asian Haze, for example, social media allowed the acquisition of information from the general population in this regard, which is key in determining how citizens are coping (Zhang et al., 2014). (3) Social media has also proven to be useful for coordinating response to a crisis. For example, it can be used to ask for donations, provide help, or to gather supplies such as temporary accommodation or food (Wan Hussin et al., 2016).

Social media can also be used with a long-term focus, in order to raise awareness about key issues (Roshandel Arbatani et al., 2016). The air pollution movement in China (2011-2012), for instance, used social media for "illustrating the size and impacts of particulate matter in accessible ways" (Fedorenko and Sun, 2016). Social media is also a valuable medium to encourage attitudinal and behavioural change, for example, through sharing adaptation strategies and measures that citizens can adopt to tackle air pollution (Kay et al., 2015). Alternatively, social media can function as an effective platform to encourage debate between experts and community members. In the aftermath of the 2011 Thai flood crisis, social media was used to "share compassionate stories, obtain emotional and physical support from their peers" which helped in the recovery process (Kaewkitipong et al., 2016). Finally, social media can also be employed to campaign in relation to an environmental injustice or problem, fostering collective action, group identity, and a sense of belonging to a community (Xu, 2014). This last usage of social media is especially relevant for countries, such as China, where public gatherings of any political nature are prohibited.

Social media facilitates an important three-way process. In social media, downstream approaches from experts to the public coexist with "horizontal interactions" between citizens (Fedorenko and Sun, 2016), alongside an upstream approach where citizens take the lead: "the power previously contained in the hands of government agencies shifts to the people" (Leong et al., 2015, p. 193). In the face of this democratisation in the communication process, different studies highlight the importance of having a person or a 
Table 1. A list of the 50 articles analysed in the systematic review. Each article is accompanied by the following information: authors, title, country in which the communication was implemented, the environmental hazard it relates to, and the main communication format it focuses on.

\begin{tabular}{|c|c|c|c|c|}
\hline Authors & Title & Country & $\begin{array}{l}\text { Environmental } \\
\text { hazard }\end{array}$ & $\begin{array}{l}\text { Communication } \\
\text { format }\end{array}$ \\
\hline Aisha et al. (2015) & $\begin{array}{l}\text { Exploring the Use of Social Media During the } 2014 \\
\text { Flood in Malaysia }\end{array}$ & Malaysia & Flooding & Social media \\
\hline $\begin{array}{l}\text { Al-Saggaf and Simmons } \\
(2015)\end{array}$ & $\begin{array}{l}\text { Social media in Saudi Arabia: Exploring its use during } \\
\text { two natural disasters }\end{array}$ & Saudi Arabia & Flooding & Social media \\
\hline Bormann et al. (2012) & $\begin{array}{l}\text { Adaptation of water management to regional climate } \\
\text { change in a coastal region - Hydrological change vs. } \\
\text { community perception and strategies }\end{array}$ & Germany & Flooding & Forum \\
\hline Bosschaart et al. (2016) & $\begin{array}{l}\text { Designing a flood-risk education program in the Nether- } \\
\text { lands }\end{array}$ & The Netherlands & Flooding & $\begin{array}{l}\text { Educational pro- } \\
\text { gramme }\end{array}$ \\
\hline Bosschaart et al. (2016) & $\begin{array}{l}\text { Evaluating a flood-risk education program in the } \\
\text { Netherlands }\end{array}$ & The Netherlands & Flooding & $\begin{array}{l}\text { Educational pro- } \\
\text { gramme }\end{array}$ \\
\hline Breuer et al. (2017) & $\begin{array}{l}\text { Exploring the application of a flood risk management } \\
\text { Serious Game platform }\end{array}$ & Germany & Flooding & Serious games \\
\hline Bunce et al. (2012) & $\begin{array}{l}\text { Exploring information experience using social media } \\
\text { during the } 2011 \text { Queensland floods: A pilot study }\end{array}$ & Australia & Flooding & Social media \\
\hline $\begin{array}{l}\text { DeForest Hauser et al. } \\
\text { (2015) }\end{array}$ & $\begin{array}{l}\text { Passive samplers and community science in regional air } \\
\text { quality measurement, education and communication }\end{array}$ & USA & Air pollution & Citizen science \\
\hline Demir (2014) & $\begin{array}{l}\text { Interactive web-based hydrological simulation system } \\
\text { as an education platform }\end{array}$ & USA & Flooding & $\begin{array}{l}\text { Educational pro- } \\
\text { gramme }\end{array}$ \\
\hline Elnokaly et al. (2008) & $\begin{array}{l}\text { Engaging architects and architectural students in global } \\
\text { warming awareness }\end{array}$ & Egypt & Air pollution & $\begin{array}{l}\text { Educational pro- } \\
\text { grammes }\end{array}$ \\
\hline Fedorenko and Sun (2016) & $\begin{array}{l}\text { Microblogging-Based Civic Participation on Environ- } \\
\text { ment in China: A Case Study of the PM } 2.5 \text { Campaign }\end{array}$ & China & Air pollution & Social media \\
\hline Felicio et al. (2014) & $\begin{array}{l}\text { Stop disasters game experiment with elementary school } \\
\text { students in Rio de Janeiro: Building safety culture }\end{array}$ & Brazil & Flooding & Serious Games \\
\hline Fritze and Kray (2015) & $\begin{array}{l}\text { Community and governmental responses to an urban } \\
\text { flash flood }\end{array}$ & Germany & Flooding & Social media \\
\hline Jiao et al. (2015) & $\begin{array}{l}\text { Application of citizen science risk communication tools } \\
\text { in a vulnerable urban community }\end{array}$ & USA & Air pollution & Citizen science \\
\hline Kaewkitipong et al. (2012) & $\begin{array}{l}\text { Lessons learned from the use of social media in com- } \\
\text { bating a crisis: A case study of } 2011 \text { Thailand flooding } \\
\text { disaster }\end{array}$ & Thailand & Flooding & Social media \\
\hline Kaewkitipong et al. (2016) & $\begin{array}{l}\text { A community-based approach to sharing knowledge be- } \\
\text { fore, during, and after crisis events: A case study from } \\
\text { Thailand }\end{array}$ & Thailand & Flooding & Social media \\
\hline Kay et al. (2015) & $\begin{array}{l}\text { Can Social Media Clear the Air? A Case Study of the } \\
\text { Air Pollution Problem in Chinese Cities, }\end{array}$ & China & Air pollution & Social media \\
\hline Kongthon et al. (2012) & $\begin{array}{l}\text { The role of Twitter during a natural disaster: Case study } \\
\text { of } 2011 \text { Thai Flood }\end{array}$ & Thailand & Flooding & Social media \\
\hline Kongthon et al. (2014) & $\begin{array}{l}\text { The role of social media during a natural disaster: A } \\
\text { case study of the } 2011 \text { Thai flood }\end{array}$ & Thailand & Flooding & Social media \\
\hline Le Coz et al. (2016) & $\begin{array}{l}\text { Crowdsourced data for flood hydrology: Feedback from } \\
\text { recent citizen science projects in Argentina, France and } \\
\text { New Zealand }\end{array}$ & $\begin{array}{l}\text { Argentina, France, } \\
\text { New Zealand }\end{array}$ & Flooding & Citizen science \\
\hline Leon et al. (2015) & $\begin{array}{l}\text { Supporting Local and Traditional Knowledge with } \\
\text { Science for Adaptation to Climate Change: Lessons } \\
\text { Learned from Participatory Three-Dimensional Model- } \\
\text { ing in BoeBoe, Solomon Islands }\end{array}$ & Solomon Islands & Flooding & Forums \\
\hline
\end{tabular}


Table 1. Continued.

\begin{tabular}{|c|c|c|c|c|}
\hline Authors & Title & Country & $\begin{array}{l}\text { Environmental } \\
\text { hazard }\end{array}$ & $\begin{array}{l}\text { Communication } \\
\text { format }\end{array}$ \\
\hline Leong et al. (2015) & $\begin{array}{l}\text { ICT-enabled community empowerment in crisis re- } \\
\text { sponse: Social media in Thailand flooding } 2011\end{array}$ & Thailand & Flooding & Social media \\
\hline Lo et al. (2013) & $\begin{array}{l}\text { Reciprocity as deliberative capacity: Lessons from a } \\
\text { citizen's deliberation on carbon pricing mechanisms in } \\
\text { Australia }\end{array}$ & Australia & Air pollution & Forums \\
\hline Mackay et al. (2015) & $\begin{array}{l}\text { Digital catchment observatories: A platform for en- } \\
\text { gagement and knowledge exchange between catch- } \\
\text { ment scientists, policy makers, and local communities: } \\
\text { DIGITAL CATCHMENT OBSERVATORY: AIDING } \\
\text { STAKEHOLDER ENGAGEMENT }\end{array}$ & UK & Flooding & Citizen science \\
\hline Mao and Pan (2014) & $\begin{array}{l}\text { Constructing the cultural repertoire in a natural disaster: } \\
\text { The role of social media in the Thailand flood of } 2011\end{array}$ & Thailand & Flooding & Social media \\
\hline McCallum et al. (2016) & $\begin{array}{l}\text { Technologies to Support Community Flood Disaster } \\
\text { Risk Reduction }\end{array}$ & China & Flooding & Social media \\
\hline McCormick (2012) & $\begin{array}{l}\text { After the cap: Risk assessment, citizen science and dis- } \\
\text { aster recovery }\end{array}$ & USA & Air pollution & Citizen science \\
\hline $\begin{array}{l}\text { Moreno Ramírez et al. } \\
\text { (2015) }\end{array}$ & $\begin{array}{l}\text { Pollution Prevention through Peer Education: A Com- } \\
\text { munity Health Worker and Small and Home-Based } \\
\text { Business Initiative on the Arizona-Sonora Border }\end{array}$ & USA & Air pollution & $\begin{array}{l}\text { Educational pro- } \\
\text { grammes }\end{array}$ \\
\hline Naik (2016) & $\begin{array}{l}\text { A crowdsourced sensing system for disaster response: } \\
\text { A case study }\end{array}$ & China & Flooding & Citizen science \\
\hline Ngo et al. (2017) & $\begin{array}{l}\text { Why participation matters for air quality studies: risk } \\
\text { perceptions, understandings of air pollution and mobi- } \\
\text { lization in a poor neighborhood in Nairobi, Kenya }\end{array}$ & Kenya & Air pollution & Forums \\
\hline $\begin{array}{l}\text { Rebolledo-Mendez et al. } \\
\text { (2009) }\end{array}$ & $\begin{array}{l}\text { Societal impact of a serious game on raising public } \\
\text { awareness: The case of FloodSim }\end{array}$ & UK & Flooding & Serious games \\
\hline Rijcken et al. (2012) & $\begin{array}{l}\text { "SimDelta" - Inquiry into an Internet-Based Interac- } \\
\text { tive Model for Water Infrastructure Development in The } \\
\text { Netherlands }\end{array}$ & The Netherlands & Flooding & Serious games \\
\hline Rizza and Pereira (2014) & $\begin{array}{l}\text { Building a resilient community through social network: } \\
\text { Ethical considerations about the } 2011 \text { Genoa floods }\end{array}$ & Italy & Flooding & Social media \\
\hline $\begin{array}{l}\text { Rodriguez Bermúdez et al. } \\
\text { (2015) }\end{array}$ & $\begin{array}{l}\text { ECity: Virtual city environment for engineering prob- } \\
\text { lem based learning }\end{array}$ & Europe & Air pollution & Serious games \\
\hline $\begin{array}{l}\text { Roshandel Arbatani et al. } \\
\text { (2016) }\end{array}$ & $\begin{array}{l}\text { Effects of Social Media on the Environmental Protec- } \\
\text { tion Behaviour of the Public (Case Study: Protecting } \\
\text { Zayandeh-Rood River Environment) }\end{array}$ & Iran & Air pollution & Social media \\
\hline Rothkrantz (2016) & Flood control of the smart city Prague & Czech Republic & Flooding & Serious games \\
\hline Salvati et al. (2016) & $\begin{array}{l}\text { Communication strategies to address geo-hydrological } \\
\text { risks: the POLARIS web initiative in Italy }\end{array}$ & Italy & Flooding & Social media \\
\hline Santos et al. (2012) & $\begin{array}{l}\text { Changing environmental behaviors through } \\
\text { smartphone-based augmented experiences., } 2012\end{array}$ & Portugal & Air pollution & $\begin{array}{l}\text { Educational pro- } \\
\text { grammes }\end{array}$ \\
\hline Savic et al. (2016) & $\begin{array}{l}\text { Serious gaming for water systems planning and man- } \\
\text { agement }\end{array}$ & The Netherlands & Flooding & Serious games \\
\hline Senaratna et al. (2013) & $\begin{array}{l}\text { Natural hazards and climate change in Kenya: Mini- } \\
\text { mizing the impacts on vulnerable communities through } \\
\text { early warning systems }\end{array}$ & Kenya & Flooding & Forums \\
\hline Sîrbu et al. (2015) & $\begin{array}{l}\text { Participatory patterns in an international air quality } \\
\text { monitoring initiative }\end{array}$ & $\begin{array}{l}\text { Belgium, Germany, } \\
\text { UK, Italy }\end{array}$ & Air pollution & Citizen science \\
\hline
\end{tabular}


Table 1. Continued.

\begin{tabular}{|c|c|c|c|c|}
\hline Authors & Title & Country & $\begin{array}{l}\text { Environmental } \\
\text { hazard }\end{array}$ & $\begin{array}{l}\text { Communication } \\
\text { format }\end{array}$ \\
\hline St. Denis et al. (2014) & $\begin{array}{l}\text { Mastering social media: An analysis of Jefferson } \\
\text { County's communications during the } 2013 \text { Colorado } \\
\text { floods }\end{array}$ & USA & Flooding & Social media \\
\hline Starkey et al. (2017) & $\begin{array}{l}\text { Demonstrating the value of community-based ("citi- } \\
\text { zen science") observations for catchment modelling and } \\
\text { characterisation }\end{array}$ & UK & Flooding & Citizen science \\
\hline Wan Hussin et al. (2016) & $\begin{array}{l}\text { Knowledge sharing via online social media during flood } \\
\text { disaster events: A review }\end{array}$ & Australia & Flooding & Social media \\
\hline Ward et al. (2016) & $\begin{array}{l}\text { Air Toxics Under the Big Sky: examining the effective- } \\
\text { ness of authentic scientific research on high school stu- } \\
\text { dents' science skills and interest }\end{array}$ & USA & Air pollution & $\begin{array}{l}\text { Educational pro- } \\
\text { grammes }\end{array}$ \\
\hline $\begin{array}{l}\text { Whatmore and Landström } \\
\text { (2011) }\end{array}$ & Flood apprentices: an exercise in making things public & UK & Flooding & Forums \\
\hline Wister et al. (2016) & $\begin{array}{l}\text { Emergency population warning about floods by social } \\
\text { media }\end{array}$ & Unspecified & Flooding & Social media \\
\hline Xu (2014) & $\begin{array}{l}\text { Communicating the right to know: Social media in the } \\
\text { do-it-yourself air quality testing campaign in Chinese } \\
\text { cities }\end{array}$ & China & Air pollution & Social media \\
\hline Yadav and Rahman (2016) & $\begin{array}{l}\text { The social role of social media: the case of Chennai } \\
\text { rains- } 2015\end{array}$ & China & Flooding & Social media \\
\hline Zhang et al. (2014) & $\begin{array}{l}\text { Usage of social media and smartphone application in } \\
\text { assessment of physical and psychological well-being of } \\
\text { individuals in times of a major air pollution crisis }\end{array}$ & Southeast Asia & Air pollution & Social media \\
\hline
\end{tabular}

team dedicated to managing social media communications, before, during, and after a crisis. Constant interaction as well as tirelessly responding to questions and comments is key to counteracting misinformation and rumours with real and valid information (Wan Hussin et al., 2016; Xu, 2014). The fact that anyone can post information on social media, and that there is no quality control over what gets posted, can be a limitation inherent to this medium. People receiving incorrect information on how to behave during a flood, or people taking advantage of flood incidents by failing to pass on donations to victims are two examples of such a limitation (Wan Hussin et al., 2016). On a more practical basis, different studies highlight the importance of using hashtags to help channel the discussion and the communication efforts to relevant people or to interested parties (St. Denis et al., 2014). Additionally, social media appears to be a medium for concise and brief information. Twitter in particular has a character limit on tweets and it is commonplace to find messages containing links to external resources and more detailed information (St. Denis et al., 2014).

\subsection{Education programmes: raising awareness}

If the systematic review found that social media is suitable for short- and long-term communication, then educational programmes are used solely with a long-term focus, namely, to raise awareness or promote a certain behaviour. An educational programme implemented in Arizona, for example, was designed to help home-based and hard-to-reach businesses (e.g. a beauty salon or a printers) in becoming green. The aim was to help them transition towards less-toxic substances, as well as to encourage these professionals to reuse and recycle materials (Moreno Ramírez et al., 2015). In the Netherlands, an educational programme had the aim of improving the understanding of hydrological concepts, and enhancing preparedness intentions of 15-year-old students (Bosschaart et al., 2016; Demir, 2014).

Educational programmes appear to follow a downstream approach, meaning that although communication flows from expert to public and vice versa, it is the experts who initiate the communication process, that is, the ones to design, organize, and set up the educational programme. Different studies agree on the benefits of implementing these programmes with the help of opinion leaders, that is, figures who are respected, perceived as being knowledgeable, and who hold higher levels of trust than, for instance, government officials. Opinion leaders are usually close, or have access, to the community or segment of the population at which the programme is aimed. In the programme implemented in Arizona, female Hispanic community health workers (called "promotoras") were invited to run the programme. They possess leadership skills that allow them to effectively influence their commu- 
nity (Moreno Ramírez et al., 2015). They are trusted because they have been trained in public health issues, and because they are "indigenous to the community" (Moreno Ramírez et al., 2015). Sometimes, the figure of the opinion leader is interchanged with that of a mediator. In cases where the programme is designed to be implemented in schools, for example, school teachers become mediators, whose job it is to guide the learning (e.g. Bosschaart et al., 2016), and the experts behind the programme design (e.g. scientists or local governments) remain as an available resource throughout the programme. It is commonplace that these intermediaries receive specific training on how to run the programme. In the case of the "promotoras", for instance, they received expert training and necessary materials to provide real-world application for specific business needs that can translate into positive change (Moreno Ramírez et al., 2015).

Educational programmes are characterised as being highly interactive. This interactivity is sometimes achieved by incorporating virtual reality technology, allowing visualisations, simulations, and animations that allow people to observe, say, different flooding scenarios and their consequences in real time (Demir, 2014), which would be impossible in real life but are important for learning (e.g. Demir, 2014). In other examples, educational programmes include inquirybased education where students are provided with equipment and training for air sampling, followed by modules addressing air pollution and health outcomes (Ward et al., 2016). Interactivity was also at the heart of another educational programme based in a school, in which pupils used old newspapers, toys, bottles, etc. from their homes to create an artwork and work with the concepts of reusing and recycling (Elnokaly et al., 2008). Another key feature of educational programmes is that often they employ real information, such as real-time flood conditions or inundation maps (Demir, 2014). Additionally, the systematic review shows that educational programmes need an element of fun, have to be easy to develop, and should offer the appropriate training when more technical knowledge is involved.

\subsection{Serious games: raising awareness}

Just as with educational programmes, serious games are reserved for long-term communication, to increase awareness and understanding, especially around flooding. For example, the aim of the game "Stop Disasters" is to work with concepts of resilience and resistance (Felicio et al., 2014). In "FloodSim", players implement a selection of strategies for addressing the risk of flooding based on a pre-defined budget. The game is designed to encourage players to think about what type of barriers to build, which regions to concentrate on, how much funding to allocate to maintenance, what warning systems to establish, etc. (Breuer et al., 2017).

Although serious games can be a vehicle for learning and communication in themselves (Felicio et al., 2014), they are sometimes accompanied by discussion and debate and played in classroom settings, where the teacher guides debate, answers questions, and explains concepts (Rodriguez Bermúdez et al., 2015). But the usage of serious games goes beyond schools and face-to-face workshops or events, where the debate is guided by experts (e.g. scientists). Sometimes, debate can also take place in a mediated environment, such as a blog or a wiki (Rodriguez Bermúdez et al., 2015). Although serious games allow two-way interactions between experts and non-experts, they tend to follow a top-down approach to communication. That is, experts are behind the game design and decide what content and information is included, which will, in turn, guide the concepts to be discussed with the non-experts. The United Nations, flood risk management professionals, and scientists in different universities are some of the people involved in designing serious games who may or may not be involved later in playing the game (e.g. Felicio et al., 2014; Savic et al., 2016). Some of the studies discuss the need for closer collaborations between game developers and knowledge partners so that games more closely fulfil the objective of raising awareness (Rebolledo-Mendez et al., 2009).

Different studies agree on the importance of having a binomial fun-knowledge combination. That is, the player has to be engaged, but acquiring new knowledge needs to be a requirement for success in the game: "the game can neither be a simple funny game without any learning, nor only involve difficult concepts without any incentive" (Rodriguez Bermúdez et al., 2015, p. 162). Including random features so that the flow of events can not be predicted or offering a diversity of scenarios are some of the strategies employed to keep the player engaged (Rodriguez Bermúdez et al., 2015). In order to make sure that the player is learning and making informed decisions, supporting information can be integrated into the game. For example, in eCity, players can get a short explanation of the advantages and disadvantages of possible moves (Rebolledo-Mendez et al., 2009). It seems as if educational programmes are designed to educate but need to have an element of fun, and serious games are fun but need to educate. Additionally, serious games appear to be an effective tool for improving understanding, as they offer continuous feedback to the player, avoiding the formation of misconceptions (Savic et al., 2016). They also encourage active and experiential learning, allowing players to handle datasets, modify values, and experience simulations which would be impossible or very expensive in real life (Breuer et al., 2017).

\subsection{Citizen science: raising awareness and long-term knowledge exchange}

Citizen science is also used for long-term communication, but appears to have a broader usage than that of educational programmes and serious games. Citizen science is helpful in raising awareness, but is also employed to facilitate knowledge exchange between experts and the public. "AirProbe" 
is a project that aims to raise awareness about air pollution by involving citizens in measuring air pollution in their daily life. The AirProbe project shows that involving citizens in taking measurements can be very effective in producing a positive change (Sîrbu et al., 2015). When citizen science projects aim at raising awareness, they tend to follow a downstream approach, initiated by the experts.

Citizen science projects, however, are also employed to facilitate knowledge exchange between experts and the public, or to complement or challenge expert knowledge. For example, they can be useful in gathering knowledge that would be impossible for experts alone to collect in terms of amount and accessibility. In the case of the Deepwater Horizon oil spill, a citizen science project was developed to allow citizens contribute with information of what they saw and smell, such as "smells, smoke, and other potential risk factors", which can in turn be used in decision-making and in complementing expert science (McCormick, 2012, p. 2). Furthermore, as experts and the public often work together in these projects, exchange knowledge, and discuss scientific data - as opposed to just receiving the outcomes generated by experts alone these projects have become a means of improving communication and the levels of trust in each other (Ngo et al., 2017; Thiel et al., 2014).

Across studies we find that affected or concerned citizens, who suffer the consequences of flooding or air pollution first hand, are more inclined to participate in these projects. For example, a community that is affected by a flood has more at stake, and therefore, is more inclined to produce citizen scientists and share flood observations (Le Coz et al., 2016). Similarly, residents who live nearer facilities that emanate or contain environmental contaminants are more likely to perceive the benefits of participating in a citizen science project aimed at improving their situation (Jiao et al., 2015). Learning about the environment is also another motivation to join citizen science projects, which broadens the spectrum of participants from affected communities to society at large. Schools are sometimes also involved in these projects, integrating them in their science curriculum (e.g. Sîrbu et al., 2015). All segments of the population, however, are never equally empowered to participate. For example, projects involving technology, such as social media or Dropbox (Le Coz et al., 2016), will inevitably add to the digital divide.

There are two factors that appear to be essential in citizen science projects. First, most of the studies concur that the first stage of any of these projects should involve training, and finding common ground between all the participants. Citizen science projects have a greater chance of fulfilling the established aims, if participants understand the ultimate aim of the project, how they can contribute and gain the most, how to use the necessary tools appropriately (e.g. air pollution measuring devices), and who to address if they encounter setbacks or need clarifications. Citizen science seems to work better when there is a clear and common goal for every participant involved, when beneficial outcomes for all are set (Jiao et al., 2015). Learning about data collection, creating bonds with other community members, or simply having an enjoyable experience are some of the examples that exceed the most obvious strategic goals usually coupled to these projects (e.g. improving flood management). Second, most of the studies highlight the importance of feeding back the results to the group after the completion of the project. Participants must understand the overall impact of the project and how their contributions fit within it, as well as how the project, the data, and the results are going to be employed (Le Coz et al., 2016).

\subsection{Forums: long-term knowledge exchange}

Discussion forums are used for long-term communication. They are the only medium solely used for knowledge exchange practices, and to bring together local and scientific knowledge. Slightly more examples of forums are found in relation to flooding than to air pollution. In Kenya, for example, a forum was organised by climate experts in order to seek traditional knowledge and build flood early warning systems: "local farmers are witnesses of their own environment and the first to notice changes and potential risks" and thus, "open dialog is necessary to build climate products that reflect farmers' needs in terms of warnings" (Senaratna et al., 2013, p. 11). Another air pollution forum, also in Kenya, explored how academics and local residents together could design action points to tackle the air quality issue (Ngo et al., 2017).

Forums can follow a downstream or upstream approach: they are sometimes initiated by experts who believe in the benefits of exploring the ground reality and local knowledge, or by the public who feel threatened and ignored, and consequently take action. Discussion forums are not always representative of the whole population, as participants usually belong to segments of the population that feel more empowered to participate (e.g. people with higher levels of education). Therefore, community members who participate in these forums are then in charge of passing on the information to the rest of the community. For example, if a forum deals with how to tackle flooding at the community level, the group is then in charge of preparing their community to face a possible flooding event, by organising meetings and developing training to raise awareness and prepare the community for evacuation and rescue plans (Senaratna et al., 2013).

Discussion forums are, however, a challenge, and on many occasions they begin with "palpable tension apparent" (Lo et al., 2013, p. 9). This tension can be attributed to a lack of trust in the experts, an incapacity to break down hierarchies of power and to encourage non-experts to contribute, or to the all too often technical language employed by the experts, which distances them from the public. Therefore, different studies deal with how to ease tensions. We have, consequently, identified four strategies for doing so. The first strategy involves experts and non-experts making something 
together, the benefits of which are two-fold: making something together works as a process, as a facilitatory medium taking the focus away from anything that generates tensions; but it also works as a product in order to engage the wider community when this is presented, for example, in an exhibition at the community centre, or is showcased in the community hall (Leon et al., 2015). The second strategy is found in one of the forums in the UK, which encourages participants to bring objects (e.g. maps, photos, satellite images, and even a piece of mouldy carpet) that show their connection to a flooding event, which works toward highlighting each member's connection to it (Whatmore and Landström, 2011). The third strategy is inspired by citizen science projects, through which the non-experts collect data that later guide the discussion and debate process. Asking participants to take personal exposures to particulate matter (PM), can be a starting point for the latter discussion and can aid the non-expert in building and supporting their arguments (Ngo et al., 2017). The last strategy consists of initiating the forums with an informative session. In one of the forums, for instance, specialists were invited to set the grounds for the debate, sharing information about the scientific, economic, and political implications of climate change and carbon tax. This was followed by an opportunity to respond to specific queries, and lastly participants were able to design a preferred carbon pricing policy (Lo et al., 2013).

A visual comparison of the results for all five communication formats can be found in Fig. 2.

Finally, these five formats are sometimes combined in order to facilitate their implementation and offer a more positive engagement. Sometimes educational programmes and serious games employ social media as a platform to enable discussion (e.g. Rodriguez Bermúdez et al., 2015). Citizen science initiatives also use social media, not only to facilitate discussion during the project, but also to recruit participants, answer questions, and feedback the results to the group (e.g. Le Coz et al., 2016). In some instances, citizen-sciencestyle activities can be developed as part of educational programmes to improve learning (e.g. hands-on activities, placebased learning) (e.g. Ward et al., 2016). Similarly, citizen science can also be employed as a strategy to empower citizens in their discussion and collaboration with the experts (e.g. Ngo et al., 2017). The way these can be combined also points out that social media and citizen science projects are the two most versatile formats. A visual representation of the combination of formats can be found in Fig. 3 .

\section{Conclusions}

This systematic review shows that there is no one-size-fitsall format of communication, and that the suitability of each medium is tied to the communication purpose and the people involved. Emergency communication needs the immediacy and remoteness of social media, whether it is to ex-

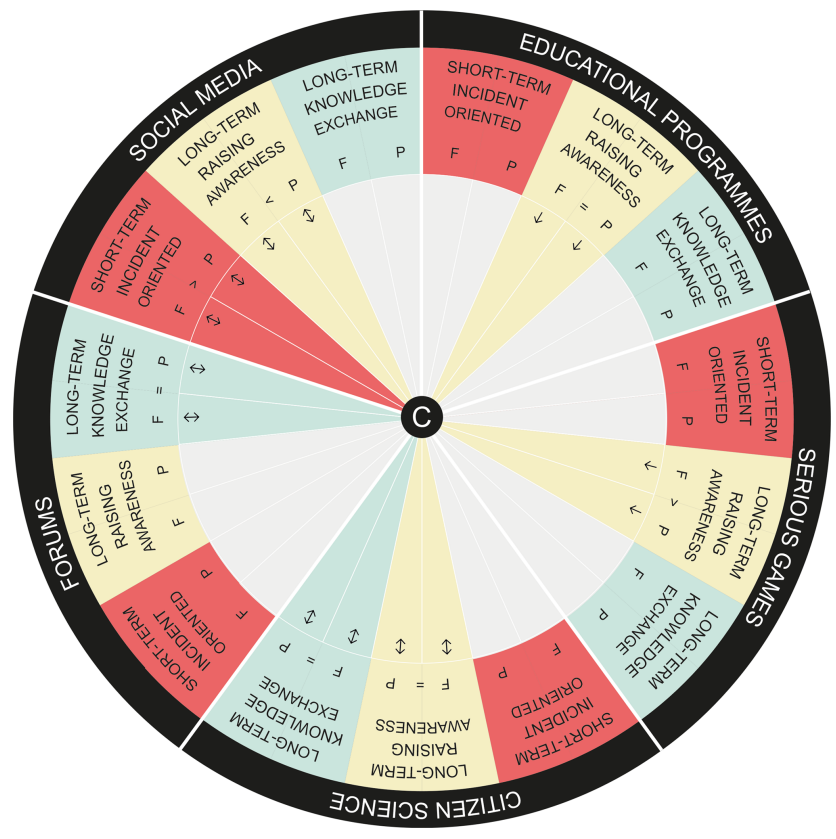

Figure 2. A comparison of how social media, educational programmes, serious games, citizen science, and forums can be used for flooding $(\mathrm{F})$ and air pollution $(\mathrm{P})$ risk. It shows whether these formats allow short-term communication, in relation to an ongoing or imminent incident; or whether it is long-term, and for raising awareness or for knowledge exchange purposes. It also shows when examples of either air pollution or flooding are more prominent than the other $(<,>)$, and if these communication formats suit both hazards to the same extent $(=)$. The grey zones represent incompatibility of the medium and usage. The arrows represent direction of communication, that is, whether communication is top-down $(\downarrow)$ and initiated by the experts, or if it can also be bottom-up $(\uparrow)$ and initiated by the public and experts alike.

change knowledge about the crisis or to coordinate a response. Expert-public partnerships for knowledge exchange purposes, on the other hand, need face-to-face encounters through forums that allow discussion and negotiation. In these two instances, the public is emotionally invested and can demand upstream approaches to communication where they can initiate the process. Raising awareness and preparedness of the population can be done through multiple media: Social media, educational programmes, serious games, and citizen science. These communication efforts are always led by experts, following a downstream approach. It is understandable that citizens would rarely demand that they are "educated", thus the lack of upstream approaches coupled to awareness-raising communication efforts. Returning to the metaphor of the ladder (Arnstein, 1969), it would seem as if only the highest forms of engagement - represented in the higher rungs - allowed upstream approaches. 


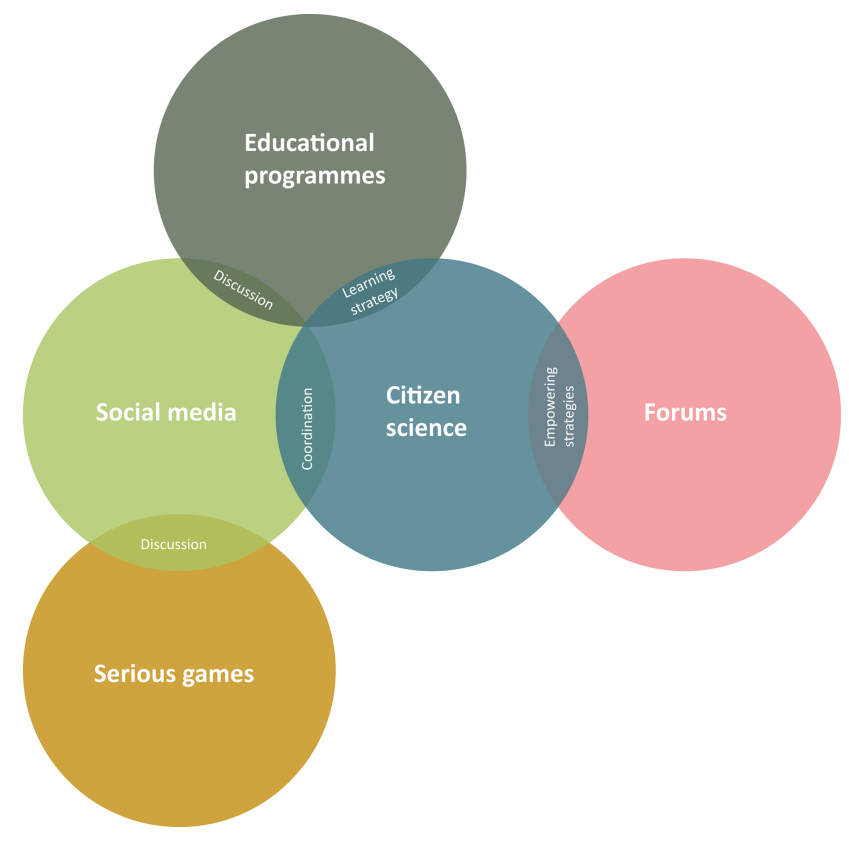

Figure 3. A visualisation of how social media, serious games, educational programmes, citizen science, and forums are currently being combined, and for what purposes.

These formats are never suitable for all segments of the population. If social media is the most democratic, it still adds to the digital divide impeding, for example, the participation of older generations. Educational programmes, for instance, target conglomerates such as schools or sector professionals, and hence these require different designs and modes of implementation. Forums, for instance, invite members of affected communities, specifically those who feel confident in meeting face-to-face with experts, and they in turn become the new experts in their communities and in charge of reaching the harder-to-reach groups in that community. Following Davies (2014) and Harvey (2008), perhaps the fact that these formats can never target society at large and that some groups tend to be excluded from these communication encounters can be understood as a call to open up the door for nondiscursive aspects (e.g. objects), aspects that will move the focus away from reasoned argument and strategic outcomes alone, and invite more diverse publics into play, where success can also be measured in terms of the experiences these encounters elicit. Opening up to forms of engagement that are more inclusive and representative is also a requirement of the "substantial" approach to public engagement previously discussed (Wilsdon and Willis, 2004).

The role of the opinion leaders or mediators is another interesting aspect. This phenomenon seems to be in line with the two-step flow of communication first proposed by Katz and Lazarsfeld (1966). Although this model of communication explains how ideas flow from mass media to opinion leaders, and from them to the sectors of the population that are less active, we also think it can be used to describe the flow of ideas from the experts to opinion leaders (e.g. community members involved in forums), to those least active segments (e.g. community members who do not feel empowered to participate). Although this seems to fulfil the purpose of trust issues, we anticipate that this might lead to governments, local authorities, or operating authorities passing on responsibility with the danger of destabilising an appropriate balance of responsibility distributed across multiple stakeholders, including the government and affected citizens. According to Johnson and Priest (2008), a shift in responsibility is already occurring: "citizens are being increasingly required to take responsibility for the management of their own flood risk at both a local community, business and individual household level" (Johnson and Priest, 2008, p. 515). They explain that those at risk need to assume the responsibility of being more prepared (e.g. household-level adaptation measures), and need to make themselves part of the decisionmaking in their community (e.g. flood risk management at the community level). We add that passing on responsibility in communication and raising awareness might also contribute further to this phenomenon.

Our analysis supports the idea that information alone is not sufficient, that communication practices appear to be difficult, and that there is a need for strategies that will break down hierarchies and distract participants from factors that can hinder the encounter, such as previous negative experiences or the lack of trust in each other, and how this is especially accentuated when the people involved in the communication process are emotionally invested (e.g. affected communities). Our systematic review shows that a key feature of effective communication, or effective usage of the selected communication formats, is to make flooding and air pollution more accessible and engagement more fun.

In relation to the independent variables, there appear to be few differences on how communication formats are employed across countries, maybe because there are not enough articles per country for differences to emerge. The only distinction is linked to countries such as China, where public meetings of any political nature, or those aimed at questioning the established order, are prohibited, and social media, thus, becomes a mechanism for mobilisation. Differences in implementation across hazards are more prominent. Social media appears to be a more popular format of communication in relation to flooding than to air pollution. Taking a closer look at social media usage, it appears that flooding requires short-term communication to deal with an imminent or ongoing event, whereas air pollution is best suited to a long-term focus in relation to improving understanding of the issue as well as modifying behaviours towards cleaner air. Although educational programmes and serious games appear to be similar in purpose and share some aspects of their implementation (e.g. binomial fun-knowledge component), the second one seems to be more popular with respect to flooding. We anticipate that this might be because of the advan- 
tages of serious games being able to have rich visualisations (flooding scenarios), which is tied to the intangibility of air pollution on the one hand, and the visibility of flooding on the other. Citizen science and forums are equally suitable for the cases of flooding and air pollution.

This systematic review offers a comparison of different two-way communication possibilities in relation to flooding and air pollution, two of the major environmental problems threatening conurbations worldwide. Its findings identify clear mechanisms to guide citizens and experts in formulating and identifying their communication needs. These findings and methodologies apply equally well whether they are in relation to flooding or air pollution or to short- or longterm communication, and whether the aim is to engage affected communities or school children.

Data availability. As this is a systematic review the underlying research data are published academic papers. The list of papers can be found in Table 1.

Author contributions. MLL conducted the systematic search, analysed the data and co-wrote the paper. SI helped with the data analysis and co-wrote the paper. PO'H, SJC, and SRH co-wrote the paper.

Competing interests. The authors declare that they have no conflict of interest.

Acknowledgements. The authors want to thank the reviewers for their helpful comments.

Edited by: Kirsten v. Elverfeldt

Reviewed by: Kirsten v. Elverfeldt and one anonymous referee

\section{References}

Abt, C. C.: Serious Games, UPA, Lanham, 2002.

Al-Saggaf, Y. and Simmons, P.: Social media in Saudi Arabia: Exploring its use during two natural disasters, Technol. Forecast. Soc., 95, 3-15, https://doi.org/10.1016/j.techfore.2014.08.013, 2015.

Amri, A., Bird, D. K., Ronan, K., Haynes, K., and Towers, B.: Disaster risk reduction education in Indonesia: challenges and recommendations for scaling up, Nat. Hazards Earth Syst. Sci., 17, 595-612, https://doi.org/10.5194/nhess-17-595-2017, 2017.

Aisha, T. S., Wok, S., Manaf, A. M. A., and Ismail, R.: Exploring the Use of Social Media During the 2014 Flood in Malaysia, Procd. Soc. Behv., 211, 931-937, https://doi.org/10.1016/j.sbspro.2015.11.123, 2015.

Arnstein, S. R.: A Ladder of Citizen Participation, JAIP, Vol. 35, No. 4, 216-224, available at: https://ithgow-schmidt.dk/ sherry-arnstein/ladder-of-citizen-participation.html (last access: 25 September 2017), 1969.
Aubert, A. H., Schnepel, O., Kraft, P., Houska, T., Plesca, I., Orlowski, N., and Breuer, L.: Studienlandschaft Schwingbachtal: an out-door full-scale learning tool newly equipped with augmented reality, Hydrol. Earth Syst. Sci. Discuss., 12, 1159111611, https://doi.org/10.5194/hessd-12-11591-2015, 2015.

Bickerstaff, K.: Risk perception research: socio-cultural perspectives on the public experience of air pollution, Environ. Int., 30, 827-840, https://doi.org/10.1016/j.envint.2003.12.001, 2004.

Bickerstaff, K. and Walker, G.: Clearing the smog? Public responses to air-quality information, Local Environ., 4, 279-294, https://doi.org/10.1080/13549839908725600, 1999.

Bickerstaff, K. and Walker, G.: Public understandings of air pollution: the 'localisation' of environmental risk, Global Environ. Chang., 11, 133-145, https://doi.org/10.1016/S09593780(00)00063-7, 2001.

Boland, A., Cherry, G., and Dickson, R.: Doing a Systematic Review, 1st Edn., Sage Publications Ltd, London, Thousand Oakes, California, 2013.

Bormann, H., Ahlhorn, F., and Klenke, T.: Adaptation of water management to regional climate change in a coastal region - Hydrological change vs. community perception and strategies, J. Hydrol., 454-455, 64-75, https://doi.org/10.1016/j.jhydrol.2012.05.063, 2012.

Bosschaart, A., van der Schee, J., and Kuiper, W.: Designing a flood-risk education program in the Netherlands, J. Environ. Educ., 47, 271-286, https://doi.org/10.1080/00958964.2015.1130013, 2016.

Bowater, L. and Yeoman, K.: Science Communication: A Practical Guide for Scientists, 1st Edn., Wiley-Blackwell, Chichester, 2012.

Breuer, R., Sewilam, H., Nacken, H., and Pyka, C.: Exploring the application of a flood risk management Serious Game platform, Environ. Earth Sci., 76, 93, https://doi.org/10.1007/s12665-0176387-1, 2017.

Bryman, A.: Social Research Methods, 4th Edn., Oxford University Press, Oxford, New York, 2012.

Bunce, S., Partridge, H., and Davis, K.: Exploring information experience using social media during the 2011 Queensland floods: A pilot study, Aust. Libr. J., 61, 34-45, 2012.

Burningham, K., Fielding, J., and Thrush, D.: "It'll never happen to me": understanding public awareness of local flood risk, Disasters, 32, 216-238, https://doi.org/10.1111/j.14677717.2007.01036.x, 2008.

Butler, C. and Pidgeon, N.: From "Flood Defence" to "Flood Risk Management": Exploring Governance, Responsibility, and Blame, Environ. Plann. C, 29, 533-547, https://doi.org/10.1068/c09181j, 2011.

Committee on Climate Change: UK Climate Change Risk Assessment 2017 Synthesis Report: priorities for the next five years, Adaptation Sub-Committee of the Committee on Climate Change, London, 2016.

Davies, S. R.: Knowing and Loving: Public Engagement beyond Discourse, Sci. Technol. Stud., 27, available at: https: //sciencetechnologystudies.journal.fi/article/view/55316 (last access: 3 November 2016), 2014.

DeForest Hauser, C., Buckley, A., and Porter, J.: Passive samplers and community science in regional air quality measurement, education and communication, Environ. Pollut., 203, 243-249, https://doi.org/10.1016/j.envpol.2014.12.028, 2015. 
Demir, I.: Interactive web-based hydrological simulation system as an education platform, Vol. 2, 910912, available at: https://www.scopus.com/inward/record. uri?eid=2-s2.0-84911906678\&partnerID=40\&md5=

793c587b9bb38747febe036436bb35dc (last access: 9 May 2017), 2014.

Elnokaly, A., Elseragy, A., and Elgebaly, I.: Engaging architects and architectural students in global warming awareness, available at: https://www.scopus.com/ inward/record.uri?eid=2-s2.0-84928436270\&partnerID= 40\&md5=717fd1e9c9553a8df386bbb955d08c4d (last access: 25 May 2017), 2008.

Environment Agency: Lessons learned: Autumn 2000 floods, Environment Agency, Bristol, 2001.

Fedorenko, I. and Sun, Y.: Microblogging-Based Civic Participation on Environment in China: A Case Study of the $\mathrm{PM}_{2.5}$ Campaign, Voluntas, 27, 2077-2105, https://doi.org/10.1007/s11266015-9591-1, 2016.

Felicio, S. P. A. S., Silva, V. S. R., Dargains, A. R., Souza, P. R. A., Sampaio, F., Carvalho, P. V. R., Gomes, J. O., and Borges, M. R. S.: Stop disasters game experiment with elementary school students in Rio de Janeiro: Building safety culture, 585-591, available at: https://www.scopus. com/inward/record.uri?eid=2-s2.0-84905841714\&partnerID= 40\&md5=929004775d6b684df4a33f4225123680 (last access: 3 May 2017), 2014.

Fohringer, J., Dransch, D., Kreibich, H., and Schröter, K.: Social media as an information source for rapid flood inundation mapping, Nat. Hazards Earth Syst. Sci., 15, 2725-2738, https://doi.org/10.5194/nhess-15-2725-2015, 2015.

Ford, J. D., Berrang-Ford, L., and Paterson, J.: A systematic review of observed climate change adaptation in developed nations, Climatic Change, 106, 327-336, https://doi.org/10.1007/s10584011-0045-5, 2011.

Fritze, H. and Kray, C.: Community and governmental responses to an urban flashflood, Proceedings of the ISCRAM 2015 Conference, Kristiansand, Norway, 2015.

Goodwin, J. and Dahlstrom, M. F.: Communication strategies for earning trust in climate change debates, WIRES Clim. Change, 5, 151-160, https://doi.org/10.1002/wcc.262, 2014.

Gravina, T., Muselli, M., Ligrone, R., and Rutigliano, F. A.: SUstaiNability: a science communication website on environmental research, Nat. Hazards Earth Syst. Sci., 17, 1437-1446, https://doi.org/10.5194/nhess-17-1437-2017, 2017.

Groulx, M., Brisbois, M. C., Lemieux, C. J., Winegardner, A., and Fishback, L.: A Role for Nature-Based Citizen Science in Promoting Individual and Collective Climate Change Action? A Systematic Review of Learning Outcomes, Sci. Commun., 39, 45-76, https://doi.org/10.1177/1075547016688324, 2017.

Harvey, M.: Drama, Talk, and Emotion: Omitted Aspects of Public Participation, Sci. Technol. Hum. Val., 34, 139-161, https://doi.org/10.1177/0162243907309632, 2008.

Illingworth, S. and Allen, G.: Effective Science Communication A practical guide to surviving as a scientist, IOP Publishing, Bristol, UK, 2016.

Jiao, Y., Bower, J. K., Im, W., Basta, N., Obrycki, J., AlHamdan, M. Z., Wilder, A., Bollinger, C. E., Zhang, T., Hatten, L. S., Hatten, J., and Hood, D. B.: Application of citizen science risk communication tools in a vulnerable ur- ban community, Int. J. Environ. Res. Pub. He., 13, 11, https://doi.org/10.3390/ijerph13010011, 2015.

Johnson, C. L. and Priest, S. J.: Flood Risk Management in England: A Changing Landscape of Risk Responsibility?, Int. J. Water Resour. D., 24, 513-525, https://doi.org/10.1080/07900620801923146, 2008.

Kaewkitipong, L., Chen, C., and Ractham, P.: Lessons learned from the use of social media in combating a crisis: A case study of 2011 Thailand flooding disaster, in: ICIS 2012 proceedings, Orlando, Florida, USA, 2012.

Kaewkitipong, L., Chen, C. C., and Ractham, P.: A communitybased approach to sharing knowledge before, during, and after crisis events: A case study from Thailand, Comput. Hum. Behav., 54, 653-666, https://doi.org/10.1016/j.chb.2015.07.063, 2016.

Katz, E. and Lazarsfeld, P. F.: Personal Influence, the Part Played by People in the Flow of Mass Communications, Transaction Publishers, New York, NY, USA, 1966.

Kay, S., Zhao, B., and Sui, D.: Can Social Media Clear the Air? A Case Study of the Air Pollution Problem in Chinese Cities, Prof. Geogr., 67, 351-363, https://doi.org/10.1080/00330124.2014.970838, 2015.

Kongthon, A., Haruechaiyasak, C., Pailai, J., and Kongyoung, S.: The Role of Twitter during a Natural Disaster: Case Study of 2011 Thai Flood, in: Technology Management for Emerging Technologies (PICMET), 2012 Proceedings of PICMET'12, Vancouver, Cannada, 2227-2232, 2012.

Kongthon, A., Haruechaiyasak, C., Pailai, J., and Kongyoung, S.: The role of social media during a natural disaster: A case study of the 2011 thai flood, International Journal of Innovation and Technology Management, 11, 1402002, https://doi.org/10.1142/S0219877014400124, 2014.

Le Coz, J., Patalano, A., Collins, D., Guillén, N. F., García, C. M., Smart, G. M., Bind, J., Chiaverini, A., Le Boursicaud, R., Dramais, G., and Braud, I.: Crowdsourced data for flood hydrology: Feedback from recent citizen science projects in Argentina, France and New Zealand, J. Hydrol., 541, 766-777, https://doi.org/10.1016/j.jhydrol.2016.07.036, 2016.

Leon, J. X., Hardcastle, J., James, R., Albert, S., Kereseka, J., and Woodroffe, C. D.: Supporting Local and Traditional Knowledge with Science for Adaptation to Climate Change: Lessons Learned from Participatory Three-Dimensional Modeling in BoeBoe, Solomon Islands, Coast. Manage., 43, 424-438, https://doi.org/10.1080/08920753.2015.1046808, 2015.

Leong, C., Pan, S. L., Ractham, P., and Kaewkitipong, L.: ICTenabled community empowerment in crisis response: Social media in Thailand flooding 2011, J. Assoc. Inf. Syst., 16, 174-212, 2015.

Lo, A. Y., Alexander, K. S., Proctor, W., and Ryan, A.: Reciprocity as deliberative capacity: Lessons from a citizen's deliberation on carbon pricing mechanisms in Australia, Environ. Plann. C, 31, 444-459, https://doi.org/10.1068/c11192, 2013.

Longnecker, N.: An integrated model of science communication More than providing evidence, JCOM - J. Sci. Commun., available at: https://jcom.sissa.it/archive/15/05/JCOM_1505_2016_ Y01, last access: 10 November 2016.

Lumbroso, D. M., Suckall, N. R., Nicholls, R. J., and White, K. D.: Enhancing resilience to coastal flooding from severe storms in the USA: international lessons, Nat. Hazards Earth Syst. Sci., 17, 1357-1373, https://doi.org/10.5194/nhess-17-1357-2017, 2017. 
Mackay, E. B., Wilkinson, M. E., Macleod, C. J. A., Beven, K., Percy, B. J., Macklin, M. G., Quinn, P. F., Stutter, M., and Haygarth, P. M.: Digital catchment observatories: A platform for engagement and knowledge exchange between catchment scientists, policy makers, and local communities: DIGITAL CATCHMENT OBSERVATORY: AIDING STAKEHOLDER ENGAGEMENT, Water Resour. Res., 51, 4815-4822, https://doi.org/10.1002/2014WR016824, 2015.

Mani, L., Cole, P. D., and Stewart, I.: Using video games for volcanic hazard education and communication: an assessment of the method and preliminary results, Nat. Hazards Earth Syst. Sci., 16, 1673-1689, https://doi.org/10.5194/nhess16-1673-2016, 2016.

Mao, M. and Pan, S. L.: Constructing the Cultural Repertoire in a Natural Disaster: The Role of Social Media in the Thailand Flood of 2011, Proceedings of the 25th Australasian Conference on Information Systems, 8th-10th December, Auckland, New Zealand, 2014.

McCallum, I., Liu, W., See, L., Mechler, R., Keating, A., Hochrainer-Stigler, S., Mochizuki, J., Fritz, S., Dugar, S., Arestegui, M., Szoenyi, M., Bayas, J.-C. L., Burek, P., French, A., and Moorthy, I.: Technologies to Support Community Flood Disaster Risk Reduction, Int. J. Disast. Risk Sc., 7, 198-204, https://doi.org/10.1007/s13753-016-0086-5, 2016.

McCormick, S.: After the cap: Risk assessment, citizen science and disaster recovery, Ecol. Soc., 17, 31, https://doi.org/10.5751/ES05263-170431, 2012.

Miller, S.: Public understanding of science at the crossroads, Public Underst. Sci., 10, 115-120, https://doi.org/10.1088/09636625/10/1/308, 2001.

Moreno Ramírez, D., Ramírez-Andreotta, M. D., Vea, L., Estrella-Sánchez, R., Wolf, A. M. A., Kilungo, A., Spitz, A. H., and Betterton, E. A.: Pollution Prevention through Peer Education: A Community Health Worker and Small and Home-Based Business Initiative on the Arizona-Sonora Border, Int. J. Environ. Res. Pub. He., 12, 11209-11226, https://doi.org/10.3390/ijerph120911209, 2015.

Naik, N.: Flooded streets - A crowdsourced sensing system for disaster response: A case study, in 2016 IEEE International Symposium on Systems Engineering (ISSE), 1-3, IEEE, Edinburgh, UK, 2016.

Ngo, N. S., Kokoyo, S., and Klopp, J.: Why participation matters for air quality studies: risk perceptions, understandings of air pollution and mobilization in a poor neighborhood in Nairobi, Kenya, Public Health, 142, 177-185, https://doi.org/10.1016/j.puhe.2015.07.014, 2017.

O'Hare, P., White, I., and Connelly, A.: Insurance as maladaptation: Resilience and the 'business as usual' paradox, Environ. Plann. C, 34, 1175-1193, https://doi.org/10.1177/0263774X15602022, 2016.

Pennington, C., Freeborough, K., Dashwood, C., Dijkstra, T., and Lawrie, K.: The National Landslide Database of Great Britain: Acquisition, communication and the role of social media, Geomorphology, 249, 44-51, https://doi.org/10.1016/j.geomorph.2015.03.013, 2015.

Petticrew, M. and Roberts, H.: Systematic Reviews in the Social Sciences: A Practical Guide, 1st Edn., John Wiley \& Sons, Malden, Mass., 2005.
Rebolledo-Mendez, G., Avramides, K., Freitas, S. D., and Memarzia, K.: Societal impact of a serious game on raising public awareness: The case of FloodSim, 15-22, available at: https://www.scopus.com/inward/ record.uri?eid=2-s2.0-70450234965\&partnerID $=40 \& \mathrm{md5}=$ d9ad929617bf0feb80c2857b3730a3e5 (last access: 3 May 2017), 2009.

Rizza, C. and Pereira, A. G.: Building a resilient community through social network: Ethical considerations about the 2011 Genoa floods, 289-293, available at: https://www.scopus. com/inward/record.uri?eid=2-s2.0-84905833904\&partnerID= 40\&md5=9a0e156e1d3ca9cf9cba9eedcdac11de (last access: 13 June 2017), 2014.

Rijcken, T., Stijnen, J., and Slootjes, N.: "SimDelta" - Inquiry into an Internet-Based Interactive Model for Water Infrastructure Development in The Netherlands, Water, 4, 295-320, https://doi.org/10.3390/w4020295, 2012.

Rodriguez Bermúdez, M., Caeiro Rodriguez, M., Llamas Nistal, M., De Carvalho, C. V., and Nogueira, F.: ECity: Virtual city environment for engineering problem based learning, Vol. 2015April, 159-166, Proceedings of the 2015 IEEE Global Engineering Education Conference (EDUCON), Tallin, Estonia, 2015.

Roshandel Arbatani, T., Labafi, S., and Robati, M.: Effects of Social Media on the Environmental Protection Behaviour of the Public (Case Study: Protecting Zayandeh-Rood River Environment), Int. J. Environ. Res., 10, 237-244, 2016.

Rothkrantz, L. J. M.: Flood control of the smart city Prague, in: 2016 Smart Cities Symposium Prague (SCSP), 1-7, 2016.

Saldana, J.: The Coding Manual for Qualitative Researchers, 1st Edn., Sage Publications Ltd, Los Angeles, 2009.

Salvati, P., Pernice, U., Bianchi, C., Marchesini, I., Fiorucci, F., and Guzzetti, F.: Communication strategies to address geohydrological risks: the POLARIS web initiative in Italy, Nat. Hazards Earth Syst. Sci., 16, 1487-1497, https://doi.org/10.5194/nhess16-1487-2016, 2016.

Santos, B., Romão, T., Dias, A. E., Centieiro, P., and Teixeira, B.: Changing Environmental Behaviors through Smartphone-Based Augmented Experiences, in Advances in Computer Entertainment, Vol. 7624, edited by: Nijholt, A., Romão, T., and Reidsma, D., 553-556, Springer Berlin Heidelberg, Berlin, Heidelberg, 2012.

Savic, D. A., Morley, M. S., and Khoury, M.: Serious gaming for water systems planning and management, Water Switz., 8, 456, https://doi.org/10.3390/w8100456, 2016.

Senaratna, N., Baudoin, M.-A., Oluoko-Odingo, A. A., Ajuang, L., Wepukhulu, D. W., and Mwadali, A. S.: Natural hazards and climate change in Kenya: Minimizing the impacts on vulnerable communities through early warning systems, in: Reducing Disaster: Early Warning Systems for Climate Change, 355-375, Springer, the Netherlands, 2013.

Sîrbu, A., Becker, M., Caminiti, S., De Baets, B., Elen, B., Francis, L., Gravino, P., Hotho, A., Ingarra, S., Loreto, V., Molino, A., Mueller, J., Peters, J., Ricchiuti, F., Saracino, F., Servedio, V. D. P., Stumme, G., Theunis, J., Tria, F., and Van Den Bossche, J.: Participatory patterns in an international air quality monitoring initiative, PLoS ONE, 10, e0136763, https://doi.org/10.1371/journal.pone.0136763, 2015. 
Slovic, P.: Trust, Emotion, Sex, Politics, and Science: Surveying the Risk-Assessment Battlefield, Risk Anal., 19, 689-701, https://doi.org/10.1111/j.1539-6924.1999.tb00439.x, 1999.

Starkey, E., Parkin, G., Birkinshaw, S., Large, A., Quinn, P, and Gibson, C.: Demonstrating the value of communitybased ("citizen science") observations for catchment modelling and characterisation, J. Hydrol., 548, 801-817, https://doi.org/10.1016/j.jhydrol.2017.03.019, 2017.

St. Denis, L. A., Palen, L., and Anderson, K. M.: Mastering social media: An analysis of Jefferson County's communications during the 2013 Colorado floods, 737-746, available at: https://www.scopus.com/inward/ record.uri?eid=2-s2.0-84905841710\&partnerID $=40 \& \mathrm{md} 5=$ $55681700 \mathrm{a} 6280 \mathrm{~d} 3 \mathrm{fd} 6882933645 \mathrm{e} 1192$ (last access: 14 June 2017), 2014.

Thiel, M., Penna-Díaz, M. A., Luna-Jorquera, G., Salas, S., Sellanes, J., and Stotz, W.: Citizen scientists and marine research: volunteer participants, their contributions, and projection for the future, Oceanogr. Mar. Biol., 52, 257-314, 2014.

Wan Hussin, W. N. T., Zakaria, N. H., and Ahmad, M. N.: Knowledge sharing via online social media during flood disaster events: A review, J. Theor. Appl. Inf. Technol., 89, 329-342, 2016.

Ward, T. J., Delaloye, N., Adams, E. R., Ware, D., Vanek, D., Knuth, R., Hester, C. L., Marra, N. N., and Holian, A.: Air Toxics Under the Big Sky: examining the effectiveness of authentic scientific research on high school students' science skills and interest, Int. J. Sci. Educ., 38, 905-921, https://doi.org/10.1080/09500693.2016.1167984, 2016.

Weingart, P. and Guenther, L.: Science communication and the issue of trust, J. Sci. Commun., 15, C01, https://doi.org/10.22323/2.15050301, 2016.
Whatmore, S. J. and Landström, C.: Flood apprentices: an exercise in making things public, Econ. Soc., 40, 582-610, https://doi.org/10.1080/03085147.2011.602540, 2011.

Whitmarsh, L.: Are flood victims more concerned about climate change than other people? The role of direct experience in risk perception and behavioural response, J. Risk Res., 11, 351-374, https://doi.org/10.1080/13669870701552235, 2008.

Wilsdon, J. and Willis, R.: See-through science: why public engagement needs to move upstream, Demos, London, 2004.

Wister, M. A., Hernández-Nolasco, J. A., Pancardo, P., Acosta, F. D., and Jara, A.: Emergency Population Warning about Floods by Social Media, in: 2016 10th International Conference on Innovative Mobile and Internet Services in Ubiquitous Computing (IMIS), 322-327, 2016.

World Economic Forum: The Global Risks Report 2016, World Econ. Forum, available at: https://www.weforum.org/reports/ the-global-risks-report-2016/, last access: 9 November 2016

$\mathrm{Xu}$, J. H.: Communicating the right to know: Social media in the do-it-yourself air quality testing campaign in Chinese cities, Int. J. Commun., 8, 1374-1393, 2014.

Yadav, M. and Rahman, Z.: The social role of social media: the case of Chennai rains-2015, Soc. Netw. Anal. Min., 6, 101, https://doi.org/10.1007/s13278-016-0410-5, 2016.

Zhang, M. W. B., Ho, C. S. H., Fang, P., Lu, Y., and Ho, R. C. M.: Usage of social media and smartphone application in assessment of physical and psychological well-being of individuals in times of a major air pollution crisis, J. Med. Internet Res., 2, e16, https://doi.org/10.2196/mhealth.2827, 2014. 